\title{
Efficacy of Pomegranate (Punica granatum L.) Peel Extracts in Suppressing Oxidation of White Coconut Oil Used for Deep Frying
}

\author{
Dilini Bopitiya and Terrence Madhujith ${ }^{1 *}$ \\ Postgraduate Institute of Science \\ University of Peradeniya \\ Sri Lanka
}

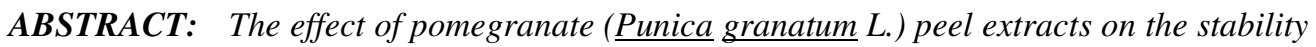
of white coconut oil during deep frying $\left(180 \pm 5{ }^{\circ} \mathrm{C} / 10 \mathrm{~min}\right)$ was determined. Antioxidative constituents present in the peel of pomegranate varieties Nayana, Daya and Nimali were extracted into acetone and incorporated into white coconut oil (WCO) at $2 \%(w / w)$ level. The WCO samples containing peel extracts were used to fry standard sized potato pieces. The oil samples were subjected to three frying cycles. After each frying cycle, oil samples (10 $m L)$ were drawn and the level of oxidation was assessed using peroxide value (PV), thiobarbituric acid reactive substances (TBARS), conjugated dienes $(C D)$ and conjugated trienes $(C T)$. $\alpha$-Tocopherol was used as the reference antioxidant and oil devoid of any additive was used as the control. Results revealed that pomegranate peel extracts from the three varieties tested are potent antioxidants that can effectively suppress oxidation and stabilize WCO during deep frying.
\end{abstract}

Keywords: Antioxidant activity, deep fat frying, pomegranate, $\underline{\text { Punica granatum }}$

\section{INTRODUCTION}

Frying is a popular method of food preparation used worldwide due to the unique sensory characteristics that develop in the food during frying process (Narasimhamurthy \& Raina, 1998; Lamboni et al., 1999; Samita et al., 2010). Due to high temperatures involved in frying and the absorption of oxygen and water, triacylglycerols (or triglycerides) undergo a series of reactions namely hydrolysis, oxidation, isomerization, and polymerization during frying (Stevenson et al., 1999; Parkash Kochhar, 2000; Abiona et al., 2011). Oxidation is among the major chemical processes that give rise to degraded products such as triacylglycerol monomers, dimers, polymers, monoacylglycerols, diacylglycerols and free fatty acids (Vieira \& Regitano-d'arce 1999; Sultana et al., 2007).

The use of oil for repeated frying is associated with development of objectionable flavor, color, and texture of fried product (Kanner \& Rosenthal, 1992; Tian et al., 2000). Some of the chemical compounds, generated through the processes of autoxidation, thermal oxidation and polymerization during repeated frying of oil are attributable to negative health effects. of these, the contribution of autoxidation process towards generation of toxicants is significant (Quiles et al., 2002; Kalogeropoulos, 2007; Pambou-tobi, et al., 2010). Many studies conclude that the oxidative stability of frying fat is an important characteristic with regards

\footnotetext{
1 Department of Food Science and Technology, University of Peradeniya, Sri Lanka

Corresponding author: madujith@yahoo.com
} 
to the quality of fried food. Gomez-Alonso et al. (2003) showed the changes in phenolic composition and antioxidant activity of virgin olive oil during frying. Shahina et al. (2005) reported the deterioration of olive, corn and soy bean oils due to deep-frying.

Antioxidants present in edible oils provide a great deal of protection for frying fats and fried foods against autoxidation through retardation of oxidative breakdown of lipids (Che Man \& Tan, 1999; Majumdar et al., 2007; Marmesat et al., 2010). However, the use of synthetic antioxidants is negatively perceived by consumers due to potential toxicity and their connotation as chemical in food (Ramalho \& Neuza Jorge, 2008; Ramadan et al., 2010). Therefore, much emphasis has recently been placed on the use of antioxidants derived from natural sources in stabilizing edible oils. Extracts of many plant materials have been reported to have varying degrees of antioxidant activities in fat and oils in food systems. Shahidi \& Bhanger (2007) studied that the stabilization of sunflower oil by garlic extract during accelerated storage. Michotte et al. (2011) reported stabilization of linseed oil with pure natural phenolic compounds.

Pomegranate peel is recognized as a potential source of antioxidants for the stabilization of food systems. Presence of substantial quantities of phenolic compounds such as ellagic tannins, ellagic acids and gallic acids has been attributed to the antioxidant potential of pomegranate peel (Yasoubi et al., 2007; Afaf-haniem et al., 2010; Ibrahium, 2010). However, the detailed information on the use of pomegranate peel extracts for stabilizing edible oil exposed to high temperature is very limited. In this backdrop, the objective of the present study was to evaluate the efficacy of peel extracts of three different varieties of pomegranate as natural antioxidants in inhibiting oxidation of white coconut oil (WCO) used for deep frying.

\section{METHODOLOGY}

\section{Materials}

White Coconut Oil (WCO) and potatoes (variety Granola) were purchased from local market. Pomegranate (Nayana, Daya and Nimali varieties) were obtained from the Regional Agriculture Research Center, Makandura, Sri Lanka. All chemicals were of the analytical grade with the highest purity available (>99.5\%) and obtained from Sigma Aldrich, USA.

\section{Preparation of stripped white coconut oil}

Stripped WCO was prepared by removing naturally occurring phenolic compounds and tocopherols by eluting WCO through a column packed with alumina (Marmesat et al., 2010).

\section{Preparation of pomegranate peel extract}

Matured pomegranate fruits were washed with pure water, peeled and the remaining edible portions were carefully separated from the peel. The peels were disintegrated into small pieces $\left(0.5 \times 0.5 \times 0.5 \mathrm{~cm}^{3}\right)$, dried in a hot air oven at $40^{\circ} \mathrm{C}$ for $48 \mathrm{~h}$. The dried fruit peel pieces were subsequently ground into a fine powder and passed through a sieve (no. 24). The prepared dried powder $(2.5 \mathrm{~g})$ was extracted into $40 \mathrm{~mL}$ of acetone through continuous stirring at a speed of $5 \mathrm{rpm}$ in an ultrasonic bath (Fisher Sonic dismembrator, model 150, USA) to increase the extraction efficiency. The resulting supernatant was filtered through Whatman No. 2 filter paper to remove particulate matter. The resulting mixture was 
desolventized at $40^{\circ} \mathrm{C}$ in vacuo (BUCHI, Switzerland). The dry extract was stored in a refrigerator $\left(4^{\circ} \mathrm{C}\right)$ until analysis.

\section{Preparation of raw potato chips}

Fresh potatoes (Granola variety) were peeled off and sliced into uniform thickness $\left(0.5 \times 0.5 \times 8.0 \mathrm{~cm}^{3}\right)$ using a mechanical slicer. The slices were kept submerged in distilled water at room temperature $\left(26 \pm 4^{\circ} \mathrm{C}\right)$. Subsequently, they were slightly blotted dry with tissue papers.

\section{Incorporation of pomegranate extracts into oil}

Pomegranate peel extracts obtained from Nayana, Daya and Nimali varieties were added into stripped WCO at $2.00 \%(\mathrm{w} / \mathrm{w})$ level and mixed well. Stripped WCO samples were brought up to $60 \pm 5^{\circ} \mathrm{C}$ before the extracts or reference antioxidant ( $\alpha$-Tocopherol) was added and subsequently the mixture was stirred for $20 \mathrm{~min}$ to ensure dissolution of antioxidant.

Extracts were incorporated according to the FDA - Food additive regulations followed by direct method.

\section{Deep Frying}

Deep fat frying was carried out in a standard size stainless steel frying pan. Raw potato chips each weighing approximately $20 \pm 0.05 \mathrm{~g}$ were introduced into stripped WCO containing pomegranate extracts or the reference antioxidant after bringing the temperature to $180 \pm 5^{\circ} \mathrm{C}$ and frying was continued for exactly $10 \mathrm{~min}$. A constant temperature of $180^{\circ} \mathrm{C}$ was maintained throughout frying. The WCO sample was reused for two more frying cycles (three frying cycles in total) over a span of three days (one frying cycle per day). Following each frying cycle, the oil was allowed to cool to $60^{\circ} \mathrm{C}$ and samples $(10.0 \mathrm{~mL})$ were drawn and stored at $-20^{\circ} \mathrm{C}$ after flushing with nitrogen until chemical analysis. A control devoid of any additive was used for comparative purposes. All frying experiments were carried out in triplicate.

The level of oxidation of frying oil after each frying cycle was assessed by determining peroxide value (PV), conjugated dienes (CD), conjugated trienes (CT) and thiobarbituric acid reactive substances (TBARS).

Peroxide value (PV) was carried out as explained by AOCS official methods Cd 8-53 (AOCS, 1997). CD and CT values were determined as explained in the analytical methods IUPAC II.D.23 (IUPAC, 1979). TBARS were measured at $530 \mathrm{~nm}$ according to the method explained by Jierong et al. (2011).

\section{Statistical analysis}

The data were analyzed using MS Office 2007 (Excel) and MINITAB version 16 programs. All measurements were performed in triplicate and results are expressed as mean \pm SD. The ANOVA tables were constructed using GLM procedure. Duncan's new multiple range test was used to determine significant differences at 0.05 significant levels. 


\section{RESULTS AND DISCUSSION}

Peroxide value (PV) is an indicator of the extent of primary oxidative products formed in oils (Shahidi and Bhanger, 2007; Jierong et al., 2011 and Michotte et al., 2011). PV of stripped WCO containing additives and the control (devoid of any additive) after each frying cycles is shown in Fig. 1. The level of oxidation gradually increased with the frying cycle for all oil systems. By the second frying cycle the effect of the additives were not significantly $(p>0.05)$ different. However, at the third frying cycle, the control showed a significantly $(p<0.05)$ higher level of oxidation as measured by PV than the oils containing pomegranate peel extracts or the reference antioxidant. There was no significant ( $>0.05)$ difference in the $\mathrm{PV}$ of the oil samples containing different pomegranate extracts. It is observed that the PV of oil samples containing the reference antioxidant, $\alpha$-tocopherol was significantly $(p<0.05)$ higher than the oil samples containing pomegranate peel extracts.

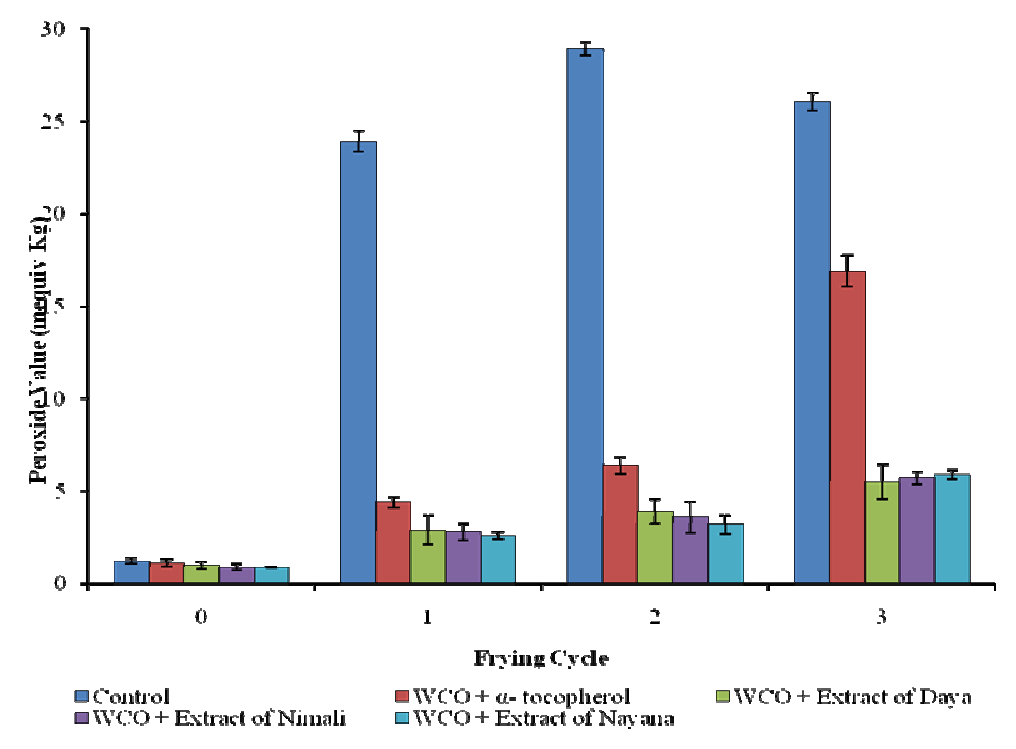

\section{Fig. 1. Peroxide value of stripped WCO containing different additives after each frying cycle.}

Relatively low PV observed in WCO samples stabilized with pomegranate peel extracts is indicative of the effectiveness of the peel extracts in mitigating oxidation of oils. Moreover, the results showed the effectiveness of the pomegranate peel extract compared to the reference antioxidant.

Edible oils stabilized with synthetic and natural antioxidants had shown low PV and extended induction periods. Sultana et al. (2007) reported that the antioxidant potential of corn cob extract in stabilizing corn oil under accelerated storage conditions. Che Man \& Tan (1999) investigated the effect of natural and synthetic antioxidants in retarding peroxide formation in palm oil during deep fat frying. It is reported that many antioxidants remain effective over a specific period of time and with the time effectiveness decreases and finally become ineffective (Shahidi and Bhanger, 2007; Marmesat et al., 2010). 
Fig. 2 and 3 illustrate the formation of CD and CT, respectively, in stripped WCO containing pomegranate peel extracts and the reference antioxidant and the control after each frying cycle. The CD and CT contents also showed a similar trend observed with PV and increased gradually with each frying cycle. The control devoid of any additive showed the highest contents of CD and CT at the end of the third frying cycle and the CD and CT values of the control was significantly $(\mathrm{p}<0.05)$ higher from the rest of the samples. The stripped WCO samples stabilized with pomegranate peel extracts showed lower levels of CD and CT compared to the reference antioxidant, $\alpha$-tocopherol indicating the effectiveness of the pomegranate peel extracts in mitigating the oxidation in oil systems. Furthermore, no significant $(\mathrm{p}<0.05)$ difference among the $\mathrm{CD}$ or $\mathrm{CT}$ values of oils containing different peel extracts was observed.

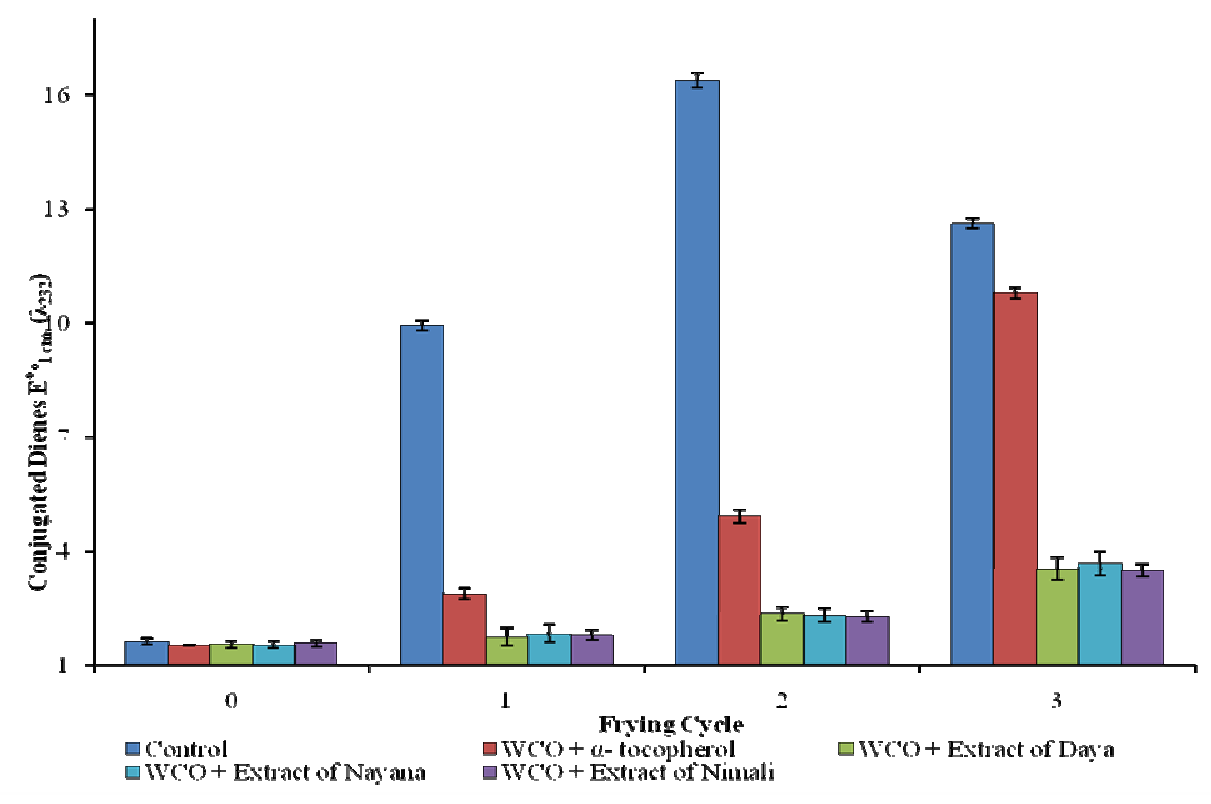

Fig. 2. Conjugated Dienes (CD) developed in stripped WCO containing different additives and control after each frying cycle. 


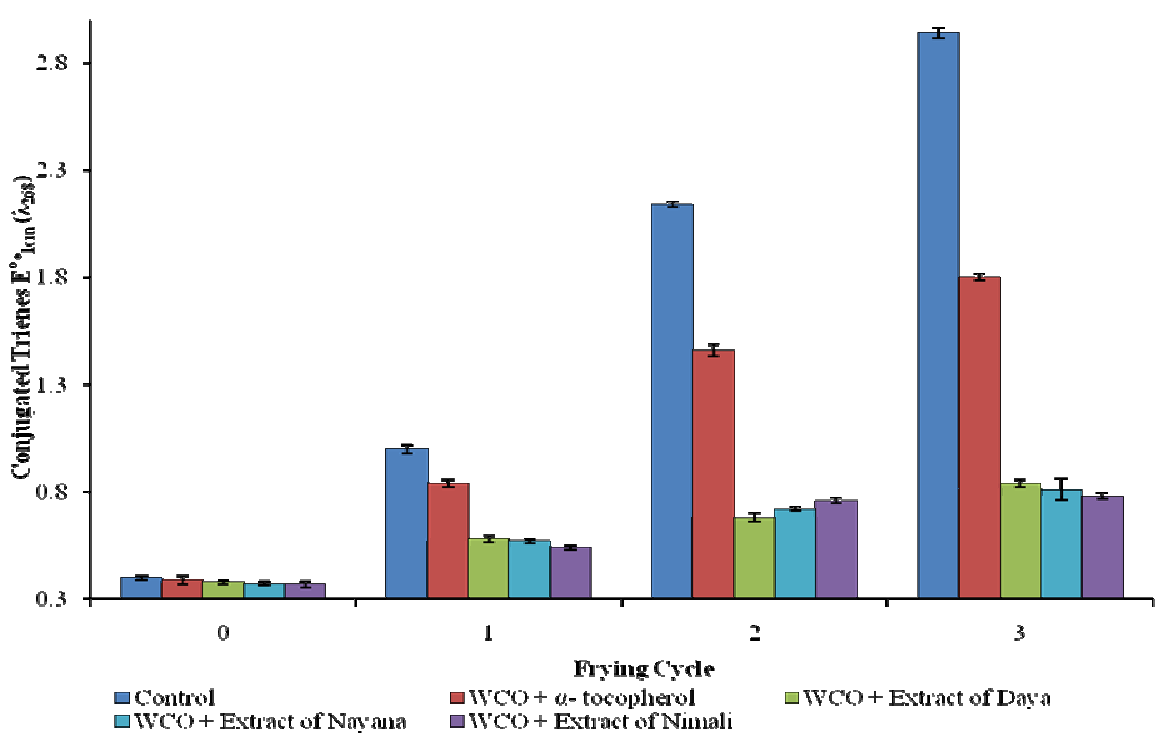

Fig. 3. Conjugated Trienes (CT) developed in stripped WCO containing different additives and control after each frying cycle.

Thiobabituric Reactive Substances (TBARS) provide a measure of the formation of secondary oxidative products mainly carbonyls which contribute to the development of offflavor in oxidized oils (Shahidi and Bhanger, 2007 and Sulthana et al., 2007). TBARS in the oil is increased gradually with frying cycles. TBARS content in stripped WCO samples containing different pomegranate peel extracts was significantly $(\mathrm{p}<0.05)$ lower than the control and the samples containing the reference antioxidant, $\alpha$-tocopherol. It is obvious that the secondary oxidative products as measured by TBARS increased with frying indicating oxidative degradation of oil systems. 


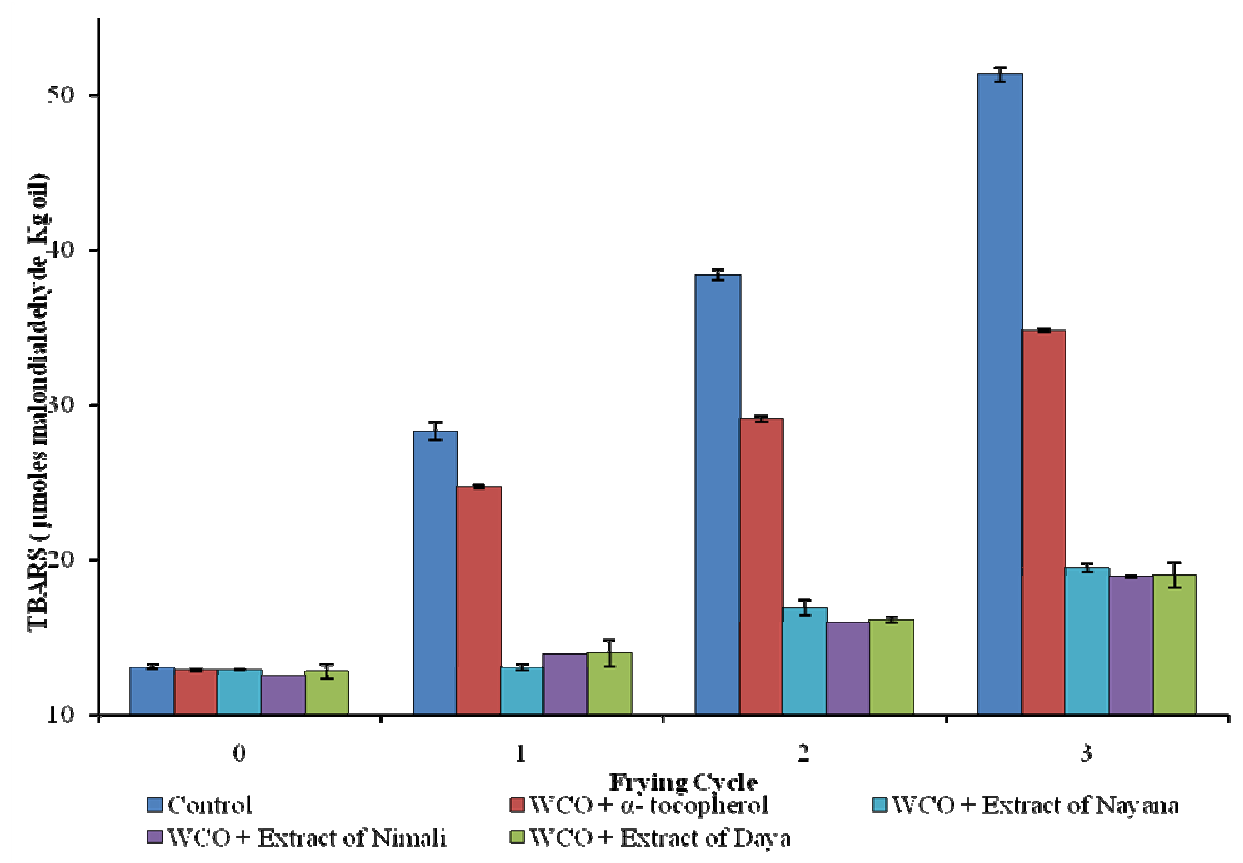

Fig. 4. Thiobabituric reactive substances (TBARS) developed in stripped WCO containing different additives and control after each frying cycle.

TBARS, PV, and CD and CT gradually increased with frying cycle in all oil systems tested indicating gradual oxidation of oil after each frying cycle. The stripped white coconut oils containing pomegranate peel extracts showed the highest resistance towards generation of oxidative products. There were no significant differences among the extracts obtained from different varieties of pomegranate tested in terms of oxidative stability as measured by TBARS, PV, and CD and CT.

\section{CONCLUSIONS}

These results illustrate that pomegranate peel extracts obtained from Nayana, Daya and Nimali varieties exhibited strong antioxidant activity in preventing oxidation of stripped white coconut during frying and the level of stabilization is even superior to that of $\alpha$ tocopherol. Therefore, it can be concluded that pomegranate peel extracts can be used to stabilize WCO against oxidation.

\section{ACKNOWLEDMENTS}

The authors thank National Research Council (NRC) for their financial support and Regional Research Station of Agriculture, Makandura, Sri Lanka for providing samples. 


\section{REFERENCES}

Abiona, O.O., Awojide, S.H., Anifowoshe, A.J., \& Babalola, O.B. (2011). Comparative study on effect of frying process on the fatty acid profile of vegetable oil and palm oil, International Scientific Research Journal 3(3), pp. 210 - 218.

AOCS (1997). Official methods recommended practiced of the American oil chemistry society $\left(5^{\text {th }}\right.$ ed.). AOCS official method cd 8-53, USA: Champaign.

Che Man, Y.B., \& Tan, C.P. (1999). Effects of natural and synthetic antioxidants on changes in refined, bleached, and deodorized palm olein during deep-fat frying of Potato chips, Journal of American Oil Chemistry Society 76(3), pp. 331 -340.

Gomez-Alonso, S., Fregapane, G., Salvdor, M.D., \& Gordon, M.H. (2003). Changes in phenolic composition and antioxidant activity of virgin olive oil during frying, Journal of Agricultural and Food Chemistry 51, pp. 667 - 672.

Ibrahium, M.I. (2010). Efficiency of pomegranate peel extract as antimicrobial, antioxidant and protective agents, World Journal of Agricultural Sciences 6(4), pp. 338 - 344.

International Union of Pure and Applied Chemistry (IUPAC) (1979). Standard methods for the analysis of oil, fat and derivatives. In C. paquot, IUPAC method II.D.23 (6 ${ }^{\text {th }}$ ed.), England: Oxford.

Jierong, Y., Mogens, L.A., \& Leif, H.S. (2011). Interaction between Tocopherols, Tocotrienols and Carotenoids during autoxidation of mixed palm olein and fish oil, Journal of Food Chemistry 127, pp. 1792 - 1797.

Kalogeropoulos, N., Salta, F.N., Chiou, A., \& Andrikopoulos, N.K. (2007). Formation and distribution of oxidized fatty acids during deep- and pan- frying of potatoes, European Journal of Lipid Science and Technology 109, pp. 1111 - 1123.

Kanner, J., \& Rosenthal, I. (1992). An assessment of lipid oxidation in foods, Pure and Applied chemistry 64(12), pp. 1959 - 1992.

Lamboni, C., Ketevi, A., Awaga, K., \& Doh, A. (1999). A study of heated vegetable oils used by street vendors in frying foods in Lome, Togo, Bulletins of Chemistry Scociety of Ethiopia 13(2), pp.173 - 177.

Majumdar, T.K., Vasudish, C.R., Premavalli, K.S., \& Bawa A.S. (2007). Stability evaluation of heated sunflower oil using rancimat, Journal of Food Science and Technology 44(2), pp.143 - 144 .

Marmesat, S., Morales, A., Velasco, J., \& Dobarganes, M.C. (2010). Action and fate of natural and synthetic antioxidants during frying, Grassas Y Aceites 61(4), pp. 333 - 340.

Michotte, D., Rogez, H., Chirinos, R., Mignolet, E., Campos, D., \& Larondelle, Y. (2011). Linseed oil stabilization with pure natural phenolic compounds, Journal of Food Chemistry 129 , pp. $1228-1231$. 
Narasimhamurthy K., \& Raina, P.L. (1998). Studies on the physico-chemical characteristics of some vegetable oils during heating and frying, Journal of Food Science and Technology 35(5), pp. $432-434$.

Pambou-tobi, N.P., Nzikou, J.M., Matos, L., Ndangui, C.B., Kimbonguila, A., Abena, A.A., Silou, T., Scher, J., \& Desobry, S. (2010). Comparative stability measurement for two frying oils: soybean oil and refined palm oil, Advance Journal of Food Science and Technology 2(1), pp. $22-27$.

Parkash Kochhar, S. (2000). Stabilization of frying oils with natural antioxidative components, European Journal of Lipid Science and Technology 102, pp. 552 - 559.

Quiles, J.L., Ramirez-Tortosa, M.C., Gomez, J.A., Huertas, J.R., \& Mataix, J. (2002). Role of vitamin $\mathrm{E}$ and phenolic compounds in the antioxidant capacity, measured by ESR, of virgin oilve, oilve and sunflower oils after frying, Journal of Food Chemistry 76, pp. 461 468.

Ramadan, Afaf-haniem, El-badrawey, S., Abd el-ghany, M., \& Nagib, R.M. (2010). Utilization of hydro-alcoholic extracts of peel and rind and juice of pomegranate as natural antioxidants in cotton seed oil. The $5^{\text {th }}$ Arab and $2^{\text {nd }}$ International Annual Scientific Conference, Mansoura University: Egypt, pp. 2442 - 2464.

Ramalho, V.C., \& Neuza, J. (2008). Antioxidant action of rosemary extract in soybean oil submitted to thermoxidation, Grasas Y Aceites 59(2), pp. 128 - 131.

Shahidi, I., \& Bhanger, M.I. (2007). Stabilization of sunflower oil by garlic extract during accelerated storage, Journal of Food Chemistry 100, pp. 246 - 254.

Shahina, N., Rahmannullah, S., Hina, S., \& Syed, A. S. (2005). Deterioration of olive, corn and soy bean oils due to air, light, heat and deep-frying, Food Research International 38, pp.127 - 134 .

Stevenson, S.G., Vaisey-genser, M., \& Eskin, N.A.M. (1999). Quality control in the use of deep frying oils, Journal of American Oil Chemistry Society 61(6), pp. 1102 - 1108.

Sultana, B., Anwar, F., \& Przybylski, R. (2007). Antioxidant potential of corncob extracts for stabilization of corn oil subjected to microwave heating, Journal of Food Chemistry 104, pp. $997-1005$.

Tian, K., Dasgupta, P.K., \& Shermer, W.D. (2000). Determination of oxidative stability of lipids in solid samples, Journal of American Oil Chemistry Society 77(3), pp. 217 - 222.

Vieira, T.M.F.S., \& Regitano-d'arce, M.A.B. (1999). Ultraviolet spectrophotometric evaluation of corn oil oxidative stability during microwave heating and oven test, Journal of Agriculture Food Chemistry 47, pp. 2203 - 2206.

Yasoubi, P., Barzegar, M., Sahari, M.A., \& Azizi, M.H. (2007). Total phenolic content and antioxidant activity of Pomegranate (Punica granatum L.) peel extracts, Journal of Agriculture Science and Technology 9, pp. 35 - 42. 